\title{
Assessing the potential of an algorithm based on mean climatic data to predict wheat yield
}

\author{
Benjamin Dumont • Vincent Leemans • Salvador Ferrandis • \\ Bernard Bodson • Jean-Pierre Destain • Marie-France Destain
}

\begin{abstract}
The real-time non-invasive determination of crop biomass and yield prediction is one of the major challenges in agriculture. An interesting approach lies in using process-based crop yield models in combination with real-time monitoring of the input climatic data of these models, but unknown future weather remains the main obstacle to reliable yield prediction. Since accurate weather forecasts can be made only a short time in advance, much information can be derived from analyzing past weather data.

This paper presents a methodology that addresses the problem of unknown future weather by using a daily mean climatic database, based exclusively on available past measurements. It involves building climate matrix ensembles, combining different time ranges of projected mean climate data and real measured weather data originating from the historical database or from realtime measurements performed in the field.

Used as an input for the STICS crop model, the datasets thus computed were used to perform statistical within-season biomass and yield prediction. This work demonstrated that a reliable predictive delay of 3-4 weeks could be obtained. In combination with a local micrometeorological station that monitors climate data in real-time, the approach also enabled us to (i) predict potential yield at the local level, (ii) detect stress occurrence and (iii) quantify yield loss (or gain) drawing on real monitored climatic conditions of the previous few days.
\end{abstract}

Keywords STICS model $\cdot$ Yield prediction $\cdot$ Real-time $\cdot$ Proxy-sensing.

Benjamin Dumont $(\bowtie)$, Vincent Leemans \& Marie-France Destain

ULg Gembloux Agro-Bio Tech, Dpt. Environmental Sciences and Technologies, 5030 Gembloux 2 Passage des Déportés, 5030 Gembloux, Belgium

e-mail: benjamin.dumont@ulg.ac.be

Tel.: +32(0)81/62.21.63, fax: +32(0)81/62.21.67

Salvador Ferrandis \& Bernard Bodson

ULg Gembloux Agro-Bio Tech, Dept. Agronomical Sciences, 5030 Gembloux, Belgium

Jean-Pierre Destain

ULg Gembloux Agro-Bio Tech - Walloon Agricultural Research Centre (CRA-W), 5030

Gembloux, Belgium 


\section{Introduction}

The use of precision agriculture technologies could address the increasing pressure for food security and sustainability and the need to halt environmental degradation (Tey and Brindal 2012). Crop models producing reliable results are interesting tools in precision agriculture, and have been successfully used to support decision-making processes and planning in agriculture (Basso et al. 2011; Ewert et al. 2011).

There are several mechanistic crop models. Some of them are specific. The CERESWheat model, for example, simulates the growth and yield of wheat (Triticum aestivum L.) taking account of the effects of weather, plant genetics, soil characteristics and management practices (Ritchie and Otter 1984; Singh et al. 2008). Other models are generic and are based on the physiological principles of growth and development that are common across crops. Well-known models include EPIC (William et al. 1989), WOFOST (Van Diepen et al. 1989), DAISY (Hansen et al. 1990), STICS (Brisson et al. 1998; 2003; 2009), SIRIUS (Jamieson et al. 1998) and SALUS (Basso and Ritchie 2005). Whatever the structure of the models, their main objective is to simulate crop growth and development in response to input variables such as soil, management practices (e.g. nitrogen supply) and climate. Most of the models work on a daily time basis and simulate the evolution of variables of interest through daily dynamic accumulation. Crop models are non-linear because of the nature of the relationships between some variables (Campbell and Norman 1989; Semenov and Porter 1995), such as the attenuation of light with leaf area index (LAI) according to Beer's law.

In order to provide the information required to optimize site-specific farming practices, however, the models need to be able to predict variability in crop quality and yield (Basso et al. $2007 ; 2011 ; 2012$ ) and to take account of intra- and inter-annual temporal variations (McBratney et al. 2005). The prediction errors of current crop models stem from a variety of uncertainties. The characterization of input variables is greatly affected by users' choices; soil properties can be defined from pedotransfer functions rather than within-field measurements; and weather data might be acquired from meteorological stations that are too far from the experimental site (Bellochi et al. 2009). Measurement uncertainties about the outputs also affect the calibration and validation of a model, and there are uncertainties in parameter assessment and in the equations constituting a model. Sometimes, although the measurements needed to run a model are not numerous, there might be considerable field spatial variability and climatic temporal fluctuations over the field. To reduce such uncertainties, the use of data assimilation systems that involve forcing the models to simulate given variables, such as the LAI, seems promising. It is important, however, that data regularly obtained from such sources as remote sensing observations (Naud et al. 2008) or proxy-sensing (Mansouri et al. 2013) are readily available.

In crop models, weather data are often the most important input data. They have a greater effect on yield than technical data and soil parameterisation (Nonhebel 1994a). The significant effect of a favourable sequence of weather conditions during a crop's growing season on the final value of its characteristics (e.g. grain yield) was highlighted by Lawless and Semenov (2005). The major climatic variables affecting yield are air temperature and precipitation (Porter and Semenov, 2005). Predictions are therefore affected by temporal fluctuations in temperature and/or precipitation, even when the mean values remain similar (Semenov and Porter 1995). The sequencing of weather events can also greatly affect dynamic crop simulations (e.g. interactive stress) (Riha et al. 1996). To overcome these problems, models are usually developed and tested using data from several years and/or sites with the aim of performing a calibration that makes them better able to respond to changes in temperatures and precipitation, given both average values and within-season variability (Riha et al. 1996). According to Nonhebel (1994a, 1994b), the simulated crop yield can be affected by considering weather averages over several days rather than day-to-day weather data, because of the non-linear behaviour of crop models. In model-based precision farming, therefore, the weather conditions need to be described as accurately as possible, using data from somewhere near the field (e.g. from small local meteorological stations).

Within the context of prediction and the need for a real-time decision-support system (DSS), crop models should be fed with data reflecting the hypothetical future. Replacing the future by forecasted weather is one way this can be done. One problem with this, however, is that forecasting is limited in time, its accuracy diminishing with long-time predictions. Another problem relates to downscaling data from a global climate model (GCM) to specific conditions. Although approaches to solving these problems fall outside the scope of this study, it is worth citing the DEMETER (Cantelaube and Terres 2003; Palmer et al. 2004; Cantelaube and Terres 2005; Challinor et al. 2005; Palmer et al. 2005) and ENSEMBLES (Hewitt 2004) projects that 
operate at the European level.

To obtain valuable results at field level, another method is based on using a stochastic weather generator (WG) (Singh and Thornton 1992; Mavromatis and Jones 1998; Mavromatis and Hansen 2001; Lawless and Semenov 2005). Based on LARS-WG (Racsko et al. 1991; Semenov and Barrow 1997), Lawless and Semenov (2005) developed a new approach for within-season yield predictions using the SIRIUS crop model. The climate information used was based on observed weather for the first part of the growing season and on 300 climate data ensembles generated by LARS-WG for the remainder of the season. The weather-series data generated through LARS-WG were representative of local conditions and were therefore site-specific. Using this approach, the authors were able to predict yields with a 90\% probability between 39 and 61 days in advance. In their analysis of four WGs, however, Mavromatis and Hansen (2001) demonstrated that the tested WGs tended to under-represent inter-annual variability in simulated yields because of a substantial bias in evaluating inter-annual variability in precipitation and temperature. They concluded that WGs would need low-frequency variability correction. Since then, as the frequency and magnitude of extreme weather events are likely to increase through climate change, the growing need to learn how weather extremes can be simulated by WGs has led to improvements (e.g. in the LARS-WG (Semenov, 2008)). Apart from this change, the use of WGs in combination with crop models requires potentially large machine resources.

In essence, it would be useful to have a fast-computing model-based decision tool that could be used in precision farming and that relied on a biophysical crop model describing realtime crop growth under local weather conditions. The objective of this paper is to present a new methodology for predicting final yield both in real-time and at field level. The proposed method addresses important new issues in precision agriculture, namely taking account of inter- and intraannual weather variation. As an alternative to the use of WGs, the methodology is exclusively based on real (past and current) monitored climate data. It was developed in order to answer the question: "At a given point in the season, what is the yield that can still be expected at harvest?"

\section{Material and methods}

\section{Overview}

The methodology was built on the basis of two main tools. The first was related to measurements of agro-environmental variables during highly contrasted crop seasons and used to parameterise, calibrate and validate a soil-crop model (the STICS model). The second was a climate database based on 30 years of records and located $4 \mathrm{~km}$ from the experimental field used to feed the model and to compare simulated and actual yields during this period.

A real-time predictive system was built, based on these tools, and its ability to evaluate stress-induced yield loss and the crop's remaining yield potential at any point in the year was demonstrated. The methodology was then extended to assess the predictive abilities of the process. To achieve both goals, weather inputs were needed for the whole growing season. This paper proposes a way of overcoming the problems of incomplete or non-existent future weather observations, and discusses in detail the assumptions on which the methodology relies and the implied consequences.

The principle of the methodology can be described as follows. At a given moment $t$ of a crop lifecycle, the climate time series is composed of the measured weather data corresponding to the real growing season from seeding to time $t$ and of the daily mean of a 30-year past-climate database covering the period from $t$ to harvest. During the crop's lifecycle, the relative importance of the daily mean database decreases in favour of the measured values. From sowing to maturity, there is therefore a reduction in uncertainty about the weather under which the crop will grow during the rest of its lifecycle. This reduction leads to increased confidence in the prediction of crop behaviour.

\section{Case study}

The data used in the study are derived from an experiment designed to study the growth response of wheat (Triticum aestivum L., cultivar Julius) under different nitrogen (N) fertilisation levels and over several years of measurements. For the purposes of the study, one nitrogen rate was considered: $180 \mathrm{kgN} \cdot \mathrm{ha}^{-1}$, applied at tillering $\left(60 \mathrm{kgN} \cdot \mathrm{ha}^{-1}\right)$, redress $\left(60 \mathrm{kgN} \cdot \mathrm{ha}^{-1}\right)$ and the last-leaf stage $\left(60 \mathrm{kgN} \cdot \mathrm{ha}^{-1}\right)$. This rate reflects current $\mathrm{N}$ management common in Belgium and is close to the optimum $\mathrm{N}$ rate for crop growth under Belgian agro-environmental conditions. The crop was grown in a classic loam soil type typical of the agro-environmental conditions of Belgium's 
Hesbaye region. A wireless microsensor network was used to continuously characterize the soil (water content, suction and temperature at two depths: 30 and $50 \mathrm{~cm}$ ) and the atmosphere (radiation, temperature and relative humidity) in the experimental area, near the crop. Pluviometric and wind data were also acquired for the experimental field. Biomass (total dry matter and grain yield), plant and grain $\mathrm{N}$ concentration, and soil $\mathrm{N}$ content were measured at regular intervals during the growing seasons.

Biomass growth was monitored over three successive years (crop seasons 2008-09, 200910 and 2010-11). In 2008-2009, the yields were fairly high, probably close to the optimum for the cultivar. This was explained mainly by good weather conditions and adequate $\mathrm{N}$ rates. In the 20092010 and 2010-11 seasons, there was severe water stress, resulting in yield loss. In 2009-10, stresses occurred in early spring and early June, but were limited. In 2010-11, they occurred from February until the beginning of June. In the summer, rainfall returned and there was a good grain yield, but straw yield was low. The climatic conditions met over the three years of observations were evaluated to be contrasted enough to correctly parameterise the model in terms of crop water and thermal stresses dependence.

\section{Features and parameterization of the crop model}

The STICS soil-crop model was used in this study. Offering the ability to properly simulate the water, nitrogen and carbon balances, this model is widely used and validated over different regions in France. As Belgian growing conditions are close to the ones met in the Northern part of France, this model appeared appropriate for our studies. There is much literature on the model's formalisms and yield simulation (Brisson et al. 1998; 2003; 2009). This model requires daily weather and climate inputs (i.a. minimum and maximum temperatures, total radiation and total rainfall). For more complex formalisms on potential evapo-transpiration (PET) calculation, wind speed and vapour pressure data are needed.

The STICS model parameterisation, calibration and validation were performed on the 3 -year database described in the case study. The calibration process was performed using the DREAM algorithm (Dumont et al. 2013; Vrugt et al. 2009) for the various aspects of plant development. Table 1 presents the results of the model evaluation of total above-ground biomass and grain yield using root mean square error (RMSE), relative RMSE (i.a. the ratio between RMSE and the mean of observations - RRMSE) and normalized deviation (ND) as evaluation criteria (Dumont et al. 2013). As noted by Riha et al. (1996), crop, climate and environment systems interact strongly, as crop canopy development depends on climate and affects PET, which in turn affects induced water stress. Correctly parameterised, a model should be able to operate under any combination of climatic data input. The three years database presented as case study was used to calibrate the model on Belgian growing conditions.

Table 1: Model evaluation over three crop seasons (2008-2011)

\begin{tabular}{llll}
\hline Variable & $\begin{array}{l}\text { RMSE } \\
{\left[\mathrm{t}_{\mathrm{ha}}{ }^{-1}\right]}\end{array}$ & $\begin{array}{l}\text { RRMSE } \\
{[\%]}\end{array}$ & $\begin{array}{l}\text { ND } \\
{[\%]}\end{array}$ \\
\hline Biomass & 2.61 & 0.12 & 0.07 \\
Grain yield & 1.55 & 0.17 & -0.03 \\
\hline
\end{tabular}

To simplify the simulation process, the same management techniques were applied to each simulation. The sowing date was in late October (23 October). Each simulation was run with the sowing date as the starting point. The same soil description was used for all simulations. The soil-water content was initiated at field capacity, relating to the usual amount of rain that falls in autumn in Belgium (a mean of about $75 \mathrm{~mm}$ in October and November). The initial soil inorganic $\mathrm{N}$ content corresponded to realistic measurements performed in the 2008-2009 season. The three doses of $60 \mathrm{kgN}$ fertilizer were applied at fixed dates (i.a. tillering, redress and the last-leaf stage in the 2008-2009 season on the Julian days 445, 470 and 513, respectively). When the sowing date is the same each year, the timing of the tillering and redress stages will be fairly constant, but the occurrence of the least-leaf stage is slightly more variable. Applying $\mathrm{N}$ at a fixed date over all the simulations is therefore debatable. This approach implies that the fertiliser would not be applied according to the strict crop physiology calendar, which would lead to slightly different results in terms of final yields, but the problem would be more significant if the studied variable is grain $\mathrm{N}$ content. The important point here was to avoid $\mathrm{N}$ stress. A delay in the date of last-leaf stage $\mathrm{N}$ dose will not have physiological consequences in terms of modelling (e.g. development of thirdorder tillers, as would be the case in reality). 


\section{Building climate database ensembles}

The Ernage weather station is part of Belgium's Royal Meteorological Institute (RMI), which operates stations throughout the country. The station is $4 \mathrm{~km}$ far from the experimental field used in this study. The measurements carried out by the station involved all the daily weather and climate inputs required to run the STICS model. For the experimental seasons, the in-field wireless network data were compared with the Ernage site data. For each climate variable the results were in good agreement. The complete 30-year (1980-2010) Ernage weather database $(\boldsymbol{W D B})$ could therefore be used in the study to feed the STICS crop model. It was assumed that cultivar, soil and management remained the same for all simulations ( $c f r$. section 'Model assumptions, limitations and requirements') and therefore that the simulations carried out differed only in weather input.

The $\boldsymbol{W D B}$ has three dimensions: the first one represented the days $d$ of the crop season after sowing, varying from 1 to $N d$; the second represented the climate variable $c v$ considered, from 1 to $N c v$; and the third represented the years, with the index $i$ varying from 1 to $N y$ (number of years $=30)$. The $\boldsymbol{W D B}$ dimension was therefore denoted as $\boldsymbol{W D B}(d, c v, i)$. For a given year $i$, data could be represented by a two-dimensional matrix $\boldsymbol{M}_{i}(d, c v)$. Within each of these matrices, a climate variable $c v$ for a year $i$ was represented as a vector $\boldsymbol{V}_{\boldsymbol{i} \boldsymbol{c} \boldsymbol{v}}(d)$.

The average climatic conditions for a particular $d$-day and a given $c v$ variable (left side of Eq. 1) represented the mean value of $\boldsymbol{V}_{\boldsymbol{i} \boldsymbol{c} \boldsymbol{v}}(d)$ computed for the same day over the 30 years:

$$
\bar{V}_{c v}(d)=\frac{1}{N y} \sum_{i=1}^{N y} V_{i, c v}(d)
$$

Following this process through the $N d$ dimensions allowed us to complete the vector of mean daily values. The same process was applied for each climate variable of the $\boldsymbol{W D B}$ and the matrix of the daily mean climate variables was reconcatenated.

As time passed and past-climate data were recorded, mean values were replaced by observed data. At the end of the crop season, all the climate input variables of the model were fully observed data. Given that the average values were replaced on a 10-day basis, shown by the increasing index $j$ for each 10-day to 10-day period, it was therefore possible to generate synthetic vectors of mixed recorded past data and hypothetic mean future values. The complete set of these mixed vectors was collectively called the Vector Ensemble and denoted as $\boldsymbol{V E}$ (Fig. 1 and Eq. 2)

$$
V E_{i, c v}(d, j)= \begin{cases}\bar{V}_{c v}(d) & \text { if } d>10 \times j \\ V_{i, c v}(d) & \text { if } d \leq 10 \times j\end{cases}
$$

Since the first vector of VE was the complete mean climate, the VE dimensions were $\boldsymbol{V} \boldsymbol{E}_{i, c v}(N d, 1+N d / 10)$. Finally, any year of the $\boldsymbol{W D B}$ could be used to supply the mean projective climate, which led to 30 vector or matrix ensembles (Fig. 1).

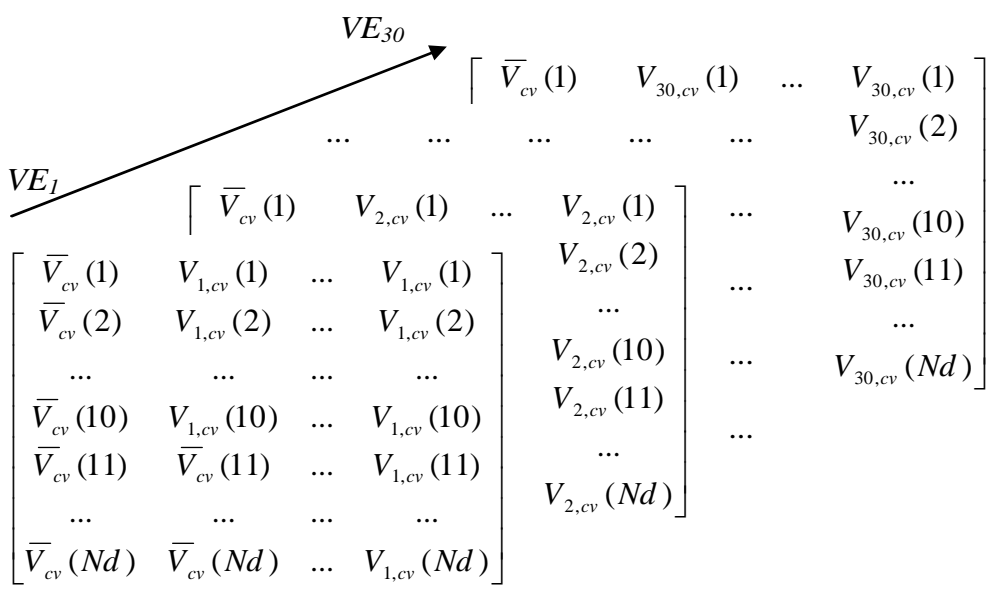

Fig. 1 Schematic bloc diagram representation of the climate database ensemble. The dimension 1 to $N d$ represents the number of days $(d)$ needed to perform a simulation of the whole growing season. The index $c v$ stands for the studied climate variable. The available $i$-years of climate data are contained in the third dimension (1 to 30$)$ 
Simulation output and results transformation

\section{Grain yield vector representation}

This paper is focused on the simulation of grain yield elaboration $(\boldsymbol{G Y})$ elaboration. Once the climate matrix ensemble was built, the STICS model was run on each weather matrix. Therefore, dynamic grain yield was considered as a function $f$ of a climate matrix $\boldsymbol{M}$, containing data from the first day of simulation until a specific number of days $d$ after sowing (1 to $d$ ). Grain yield elaboration was also studied for a particular combination of real and mean climate $(r m c)$ data included in the $[1,1+\mathrm{Nd} / 10]$ space and for a given $i$-year of the $\boldsymbol{W D B}$

$$
G Y(d, r m c, i)=f(M(1 \text { to } d, r m c, i))
$$

In terms of prediction we were interested mainly in the final value of the grain yield $(\boldsymbol{F G Y})$ obtained at the end of the season (i.a. at the $N d$ day), referred to as $\boldsymbol{G Y}(N d, r m c, i)$. For each $i$-year of the $\boldsymbol{W D B}$, it was therefore possible to construct a vector $\boldsymbol{F G} \boldsymbol{Y}_{i}$ that contained the $\boldsymbol{F G Y S}$ for each particular $r m c$ combination (i.a. for each synthetic dataset made up of a different combination of real and mean climatic data):

$$
F G Y_{i}=\left[\begin{array}{lllll}
G Y(N d, 1, i) & \ldots & G Y(N d, r m c, i) & \ldots & G Y\left(N d, 1+\frac{N d}{10}, i\right)
\end{array}\right]
$$

Let us consider an arbitrary $r m c$ value selected in the $[1,1+\mathrm{Nd} / 10]$ space. The $\boldsymbol{G Y}(\mathrm{Nd}, \mathrm{rmc}, i)$ value has to be seen as the predicted yield that would be obtained if the climate was the one observed for the year $i$ from sowing until the $\left(r m c^{*} 10\right)$ day considered (accounting for past growth conditions) and assuming that a mean climate occurred thereafter up to the time of harvest on $N d$ day.

A final transformation was applied to the latter vector to obtain the reduced grain yield vector $\boldsymbol{R} \boldsymbol{G} \boldsymbol{Y}_{\boldsymbol{i}}$ (Eq. 5). Each hypothetical climate element of a given $\boldsymbol{F} \boldsymbol{G} \boldsymbol{Y}_{i}$ vector was reduced by the final grain yield obtained with the full real climate data obtained for the $i$-year (i.a. the last element of the $\boldsymbol{F} \boldsymbol{G} \boldsymbol{Y}_{i}$ vector represented by the value $\boldsymbol{G} \boldsymbol{Y}(N d, 1+N d / 10, i)$ value). This difference showed that errors in the $\boldsymbol{F} \boldsymbol{G} \boldsymbol{Y}$ prediction (in tons per hectare, or $\mathrm{t}^{-1} \mathrm{a}^{-1}$ ) decreased with increasing knowledge about real weather conditions during the crop season. Obviously, this value tended to zero by the end of the season.

$$
\begin{aligned}
R G Y_{i} & =F G Y_{i}-G Y\left(N d, 1+\frac{N d}{10}, i\right) \\
& =\left[\begin{array}{llll}
G Y(N d, 1, i)-G Y\left(N d, 1+\frac{N d}{10}, i\right) \quad \ldots & G Y(N d, r m c, i)-G Y\left(N d, 1+\frac{N d}{10}, i\right) & \ldots & 0
\end{array}\right]
\end{aligned}
$$

\section{Statistical prediction of grain yield}

$\boldsymbol{R} \boldsymbol{G} \boldsymbol{Y}$ was computed for the 30 years of the $\boldsymbol{W D B}$. The cumulative probability density function (pdf) associated with each $r m c$ value over the 30 years was calculated. The $\boldsymbol{R} \boldsymbol{G} \boldsymbol{Y}$ pdf was estimated with the ksdensity function of Matlab. It allowed the $\boldsymbol{F} \boldsymbol{G} \boldsymbol{Y}$ to be simulated with a given error over 30 years and at any given point in the year (corresponding $r m c$ value). Since it was expressed as an error in the final simulated grain yield, the dynamic $r m c \boldsymbol{R} \boldsymbol{G} \boldsymbol{Y}$ allowed a direct comparison among the 30 simulated yields.

The immediate consequence of $\boldsymbol{F} \boldsymbol{G} \boldsymbol{Y}$ reduction was that the $\boldsymbol{R} \boldsymbol{G} \boldsymbol{Y}$ pdf was drawn around, or at least involved in, the 'zero'-value. It was therefore possible to estimate the probable interval in which the $\boldsymbol{F G Y}$ would be found. Two error levels in prediction were considered in this study, fixed at $10 \%$ and $15 \%$. For a common wheat grain yield obtained with Belgian cultivars, this corresponded to about $1 \mathrm{t}^{-h^{-1}}$ (resp. 1.5 t.ha $^{-1}$ ) absolute error.

The evolution of this probability was dynamically studied with the different $r m c$ combinations. As shown in the results section, the $r m c$-combination-dependent pdf exhibited a classic sigmoidal growth that was calculated using a Gompertz model:

$$
P(r m c)=1-\alpha=1-M \times \exp \left(-\exp \left(\frac{-(r m c-a)}{b}\right)\right)
$$

where $M, a$ and $b$ are the parameters, $r m c$ is the abscise value in terms of days of observed climate, and $P(r m c)$ is the associated probability. Finally, the primary alpha-risk was chosen, illustrating 
the degree of confidence in the prediction. By inverting Eq. 6, the date at which the alpha risk was reached was determined.

The yield prediction method, called the 'density approach', was compared with the approach used by Lawless and Semenov (2005). This latter consisted of plotting the cumulative probability distribution of the first day for which the yield could have been predicted. To do so, for a given year, a confidence interval was computed as the product between the $\boldsymbol{F} \boldsymbol{G} \boldsymbol{Y}$ value simulated on pure real climate and the error level (e.g. 10\%). It was necessary to then go back to the curve and find the first $r m c$ combination that simulated a yield outside the confidence interval. Proceeding in this way across the years allowed the cumulative probability distribution of the first day for which the yield could be predicted with confidence to be computed.

\section{Model assumptions, limitations and requirements}

In a general way, there would have an immediate advantage to use a daily mean climatic database as it corresponds to the seasonal norms, which is something determined for almost every part of the world, while accessibility to long-term historical weather records can be limited. With regards to the non-linearity of some formalisms in crop models, but considering that some cropping systems may be characterised by generally low level of stresses (e.g. under the temperate climatic conditions in Belgium), the use of mean climatic data could be of great interest but had to be evaluated. Therefore, the first and main aim of this study was thus to optimise and assess a methodology that uses a mean climate database to perform yield prediction. However, using a dynamic crop model in combination with hypothetic mean climate data is conceptually simple, but the approach is based on several strong assumptions which will be discussed here after.

It was first assumed that the STICS crop model was adequately parameterised and validated. This implied that the variability of the climate years used in these processes was great enough to correctly parameterise the different hydric and thermal stresses. With the strong stresses that occurred during the 2009-10 and 2010-11 crop seasons, it is probable that climate variability was important enough to induce the stress phenomena that occurred during the successive growth stages. This will be illustrated in the results section.

A second assumption was related to the available climate database. It is not always easy to have access to such a long-term weather series. It is also necessary for the past monitored weather database to be wide enough to reflect the entire climate variability of the studied area. In addition, the size of the database should not be too large, in order to avoid having to take early climate change effects into account.

A third assumption concerned the use of the computed mean climate matrix as the hypothetic projective climate. This implies that the corresponding simulated growth was made under low stress levels of water deficit or heat stresses. The daily precipitation, radiation and temperature values were daily averages of the same day over the past 30 years. In other words, a minimum amount of water, solar energy and sum of temperatures was available each day for the crop, which minimized stress. This growing environment was close to 'nearly non-limiting growth conditions' (referred to later in this paper). The yield thus derived and predicted should therefore be understood as the remaining yield potential.

Another aspect of the methodology is that it relies on the combination of hypothetic mean climate data and real historical data, which raises two important questions. The first concerns the independence of the climate series, and the second deals with the independence of the corresponding simulations. As the part represented by the mean projective climate was the same for all distributions, there was no independence of the climate series. This was especially true at low $r m c$ values (a short duration with independent measured data and a long period of similar mean projective climate data). In contrast, at the end of the season the historical independent climate part was the greater one. For a high $r m c$ value, data therefore become more independent. With regard to the independence of the simulations, at any moment of a plant's cycle its past growing conditions strongly influence its actual state and future, whatever the forthcoming weather. This is notably driven by the crop implantation (i.a. root density, root length, number of grain put in place) and potential biomass reallocation. Therefore, even at low $r m c$ values, the simulated plant growth will be totally different.

Finally, the mean climate data computation is equivalent to smoothing the data, which reduces intra-annual variability and the sequencing of the stress events. This, however, is the precise goal of the method. The approach developed by Lawless and Semenov (2005) offers the range of all the possible solutions. On the other side, as previously stated, the computed daily averaged climate variables are close to the seasonal norms. Thus, the approach simulates the expected remaining crop yield potential, i.e. the yield that a farmer could expect if, after stresses 
events, the weather conditions could come back close-to the normal between the considered day in the season and the time of harvest). With regard to inter-year variability, the combination over years of the mean data with the same mean projective climate is debatable early in the season (low $r m c$ values), clearly reducing climate variability. As will be illustrated, however, when the $r m c$ is low the predictive ability is weak. In contrast, with increasing $r m c$ values the predictive ability becomes significant. Thus, and with reference to the earlier note that the simulations could be considered independent, it appears reasonable to consider that the methodology preserves inter-year variability when it is necessary.

\section{Results and discussions}

\section{Single-year analysis - Assessing yield loss}

Fig. 2 shows the grain yields obtained with a given Matrix Ensemble, in this case $\boldsymbol{M E}_{26}$ (i.a. the $\boldsymbol{M E}$ based on the 2005-2006 season). This season was known for not producing high yields. Fig. 2A is the graphical presentation of the grain yield elaboration, $\boldsymbol{G Y}(d, r m c, 26)$ (Eq. 3) over the different $r m c$ combinations. Fig. 2B presents the $\boldsymbol{F G Y}$ values obtained with weather ensembles of mean and real observed data (Eq. 4). For a given day in the crop season (on the $x$ abscise), it shows the corresponding $\boldsymbol{F G Y}$ obtained if no further stress occurred before harvest, taking account of past growing conditions. The solid black line represents the grain yield obtained with a complete mean climate data ; the dotted dark line corresponds to the complete real climate data. The light grey lines (Fig. 2A) and the squared light grey line (Fig. 2B) represent the different $r m c$ combinations.

At any point in the season, even at sowing (number of observed days $=0$ ), the mean climate projection allowed the end-season grain yield (remaining grain yield potential) to be estimated. In addition, representing data this way made it possible to instantly quantify the loss, or gain due to the weather conditions over the preceding 10 days. In this way, the weather conditions of the preceding 10 days were used to determine whether or not the remaining yield potential had improved.

In this context, the 2005-2006 season was not favourable for wheat cultivation. As evident in both graphs, the weather at the beginning of the season (autumn) would have led to slightly better yields than the mean climate data suggested, but a cold winter and late spring induced delay in biomass growth recovery. Two short periods of favourable climate occurred 160 and 210 days after sowing, but the climate immediately afterwards was not conducive for maintaining potential yield, especially for a few days after anthesis, at about 240 observed days. The cold and rainy conditions in the second half of May (between observed days 180 and 210) provided no compensation for the initial delay. The scorching dry weather conditions in June (especially late June) accelerated the wheat ripening. A very hot July reduced the activity of the two last leaves, which brought harvest time forward. From the middle of March until the end of the season, therefore, no suitable weather conditions for growth were met. At the end of the season, the $\boldsymbol{G Y}$ elaboration period was shorter than initially predicted, and exhibited a lower carbohydrate accumulation rate (Fig. 2A).
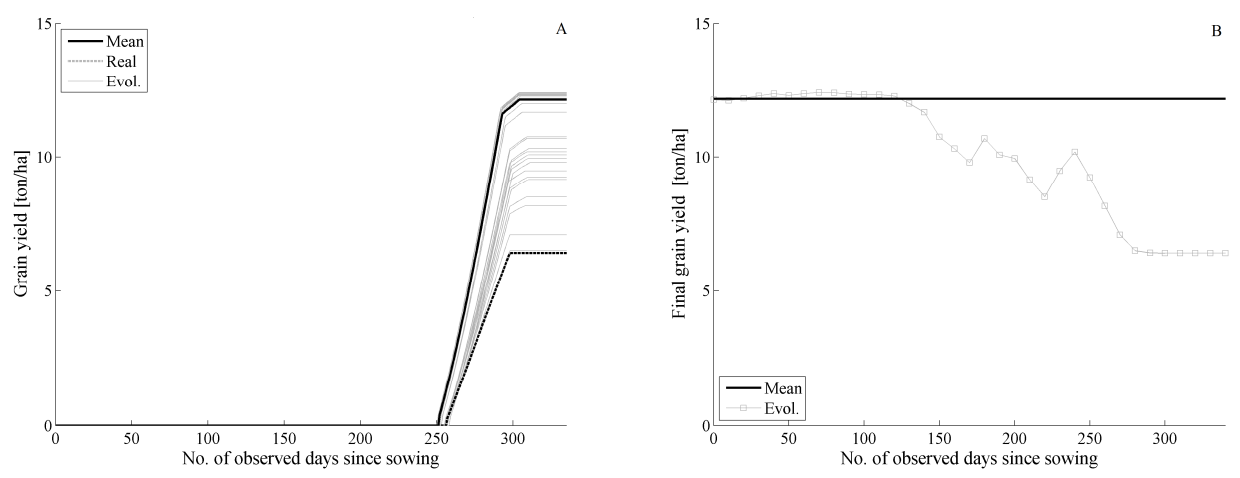

Fig. 2 Grain yield daily simulations based on the first Matrix Ensembles for the year 2005-2006 $\left(\mathrm{ME}_{26}\right)(\mathrm{A})$. Evolution of the final grain yield (FGY) vs. $r m c$ combination (B). Solid black line: full mean climate. Dotted black line: full real climate. Light grey lines (left) and squared grey line (right) : rmc combinations. 
Now being developed as a decision-support system (DSS), the proposed method should enable farmers to adapt their management strategy in real time. For example, at about the time of the third fertiliser application (usually in mid-May in Belgium), the methodology could be used to evaluate the remaining yield potential. If the potential yield gross margin would no longer compensate for fertiliser application costs, the farmer might decide not to fertilise. In the analysed case, the potential yield was about 9 t.ha $^{-1}$ (Fig. 2B), indicative of quite a good season, leading to the decision that it could be worth applying the third $\mathrm{N}$ dose. Unpredictable conditions in June and July, however, led to a decrease in yield.

In general, the proposed methodology appears to be suitable for building a real-time DSS in that, used with a real-time weather data monitoring system, it will provide a quick overview of a crop's remaining yield potential at any point in the season.

\section{Multiple-year analysis - Predicting yield}

The results obtained with the proposed method greatly depend on the chosen climatic year. In order to assess the method's potential as a predictive tool, the procedure was applied to all available observed years of the $\boldsymbol{W D B}$. Fig. 3 presents these results. Fig. 4 is based on the same results, but the values of each point on the same curve are reduced in relation to the $\boldsymbol{F G Y}$ obtained from the complete real climate data of the corresponding year. Fig. 4 is the graphical output of Eq. 5 , applied to each year of the WDB.

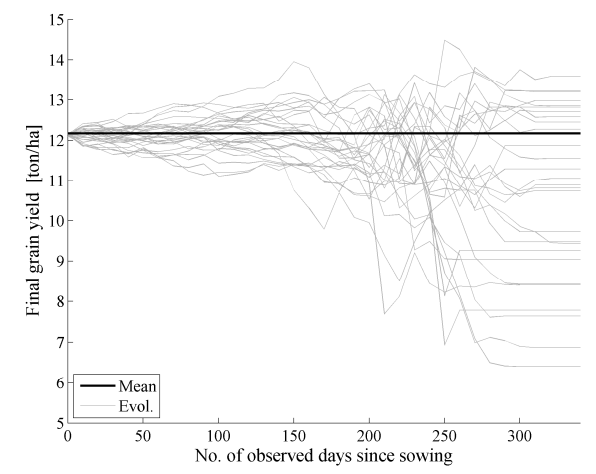

Fig. 3 Evolution of the $\boldsymbol{F G Y}$ vs. $r m c$ combination for all the Matrix Ensembles $\left(\mathrm{ME}_{1-30}\right)$. Solid black line: complete mean climate data. Light grey line: $r m c$ combinations

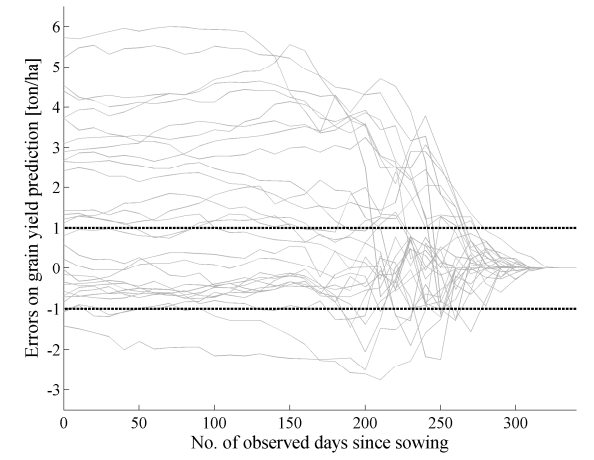

Fig. 4 Evolution of the $\boldsymbol{R} \boldsymbol{G} \boldsymbol{Y}$ vs. $r m c$ combination for all the Matrix Ensembles $\left(\mathrm{ME}_{1-30}\right)$. Dotted horizontal black line: \pm 1 t.ha ${ }^{-1}$ boundaries. Light grey line: $r m c$ combinations

As can be seen in Fig. 3, the grain yield obtained with complete real-climate simulations ranged fairly widely from \pm 6.5 to $\pm 14 \mathrm{t} \mathrm{ha}^{-1}$. This variation range accords with the observations reported by Palosuo et al. (2011), where yields ranged between 2.5 and $12.0 \mathrm{t} \mathrm{ha}^{-1}$. In addition, the simulated outputs were consistent with the yields observed during the field experiments for the crop seasons from 2008-09 to 2010-11. During these experiments, the yields were 12.6, 7.8 and $6.9 \mathrm{t} \mathrm{ha}^{-1}$, respectively. The Julius cultivar was known to have a high potential yield, and 2008-09 was a really good crop season, characterised by high temperatures and regular rainfall. In contrast, the 2010-11 season was not conducive to good yields, with an important water deficit and heating stress occurring in the spring. The low number of grains per ear, however, improved with the return of rain in early summer, but the straw yield remained very poor. These results indicated that 
the requirements of the first hypothesis (a correctly calibrated model) had been met.

The impact of the assumption to replace hypothetical future weather data with the daily mean data is clearly evident in Fig. 3. As mentioned earlier, the daily averages led to nearly nonlimiting growth conditions. This corresponded with a grain yield close to the higher yields, with a value of $\pm 12.2 \mathrm{t} \mathrm{ha}^{-1}$ (solid black line on Fig. 3). In comparison with the observation reported by Semenov and Porter (1995), the yield simulated with complete mean climate data was much closer, and even fell within the yield distribution simulated using complete real historical climate data. This supported the idea the advantage of using mean climate data as projective weather in this particular case study. Fig. 3 also shows that using complete mean climate data is not the best climatic solution, although this can lead to good grain yield simulations. Two reasons could explain this. First, depending on the way the mean climate was computed (Eq. 1), there would always be weather conditions better than the daily averages in terms of growing conditions. Although the crop responses to the environmental conditions were non-linear, it seemed that under the Belgian conditions these effects were not detrimental to the culture and did not preclude working with a mean climate projection. The highest grain yields were therefore the result of $(i)$ the time in the season when growing conditions were good, (ii) the number of consecutive days better than the average, without being detrimental, (iii) the magnitude of a such a phenomen for a given weather variable, (iv) the combination of phenomena over different variables and $(v)$ the absence of stress after these better conditions.

Second, the mean climate assumption is characterised by a plant growing environment where a minimum amount of each weather variable is present every day (e.g. rain). Apart from a few days, the mean rainfall was between 0.5 and $4 \mathrm{~mm} \mathrm{day}^{-1}$. Since evapotranspiration (ETP) could be higher at the full plant development rate, these values could have led to slight water stress in late spring and summer. As it rained every day under the mean climate assumption, however, these stresses remained limited.

Fig. 3 shows that the worst climatic conditions generally occurred around mid-April and then again after mid-May. This would have an important impact on decision making. It indicates that the impact of weather variability would be limited before May. The worst weather events occurred at the end of the growing season, after mid-May. Thus, building a DSS for $\mathrm{N}$ fertilisation would be irrelevant for first and second applications, as practised in Belgium. These observations corroborated the findings reported by Riha et al. (1996) who stated that the sequencing of weather events greatly affected dynamic crop simulations (e.g. interactive stresses). Our methodology went further, however, by identifying the weather sequences that were the most detrimental and by quantifying their negative impact.

The $\boldsymbol{R} \boldsymbol{G Y}$ computation (Fig. 4) was the next step in the methodology developed to predict grain yield in advance. In this graph, the simulations are surrounded by $\pm 1 \mathrm{t} \mathrm{ha}^{-1}$ boundaries. These boundaries could be drawn on the pdf associated with each $r m c$ combination (Fig. 5). The probability associated with a prediction of $\pm 1 \mathrm{tha}^{-1}$ can therefore be computed as the probability lying between the upper and lower boundaries. Applying the same computation to all rmc combinations led to the cumulative distribution functions of the grain yield prediction (Fig. 6, black pointed-line and Table 1).

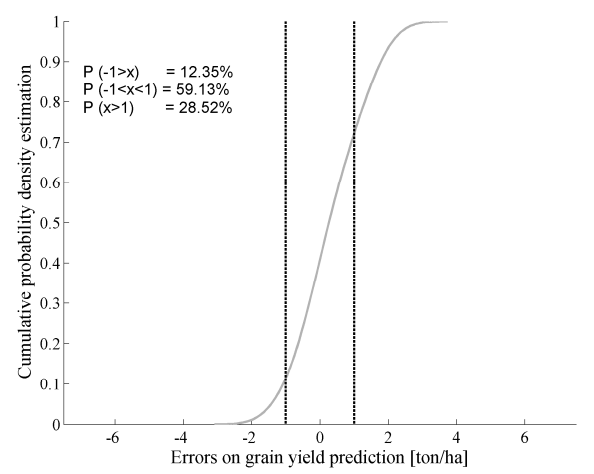

Fig. 5 Cumulative probability distribution of yield prediction as influenced by absolute yield errors $(\boldsymbol{R} G Y)$, after 260 days of observation.

Fig. 6 compares both methodologies for calculating the cumulative density function, namely the density approach developed in this paper and the determination of the first day for which prediction would have been possible. The two curves mainly differed in terms of probability of prediction between sowing and 220 days after sowing date. During this time lapse, the curve based on the density approach is more or less constant and close to 0.3 , while on the same period 
the other curve evolved logically from 0 till 0.3 . The differences between these two curves quantified thus the error associated to the density approach of yield prediction and due to the lack of independence of the climate time series. Therefore, in early season, at low $r m c$ values, the dependence of climatic series being very high, one had approximately $30 \%$ more chances (computed as the difference between the two curves) of predicting a wrong final yield while the confidence is anyway pretty low (obtained on the curve of first day of possible prediction).

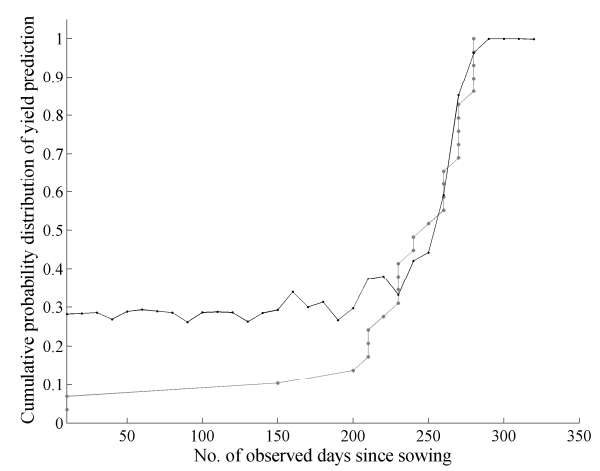

Fig. 6 Graphical comparison of predictive ability based on the determination of the first day of possible prediction (grey pointed-line) and the density method (black pointed-line), for an associated grain yield error level fixed at $10 \%$.

On the other side, from 220 days after sowing, and up to the end of the season, the two curves exhibited the same predictive ability. However, 220 days after sowing the reliability of the prediction was still pretty low, around 0.3 . One had still to wait 30 days to achieve significant confidence level of yield prediction, i.e. at least superior to 0.5. For significant confidence level, the density approach proposed in this paper appeared thus validated.

The Gompertz growth model was used for in-between point extrapolation. As detailed in Table 2, it appeared to be possible to predict wheat yields on about 19 July, with a significant probability (90\%) and a reasonable risk (10\% confidence interval). This corresponded approximately to anticipating, 3 weeks in advance, a harvest date on about 10 August in Belgium for late-maturing wheat varieties (such as Julius). Logically, the more risk that is accepted, the sooner yields can be predict reliably. In the same way, the wider the tolerance of the yield prediction boundaries, the earlier the predictions can be made (Table 1). The values presented in Table 2 are consistent with the results obtained by Lawless and Semenov (2005) and Semenov and Doblas-Reyes (2007).

Table 2 Day on which yield could be predicted, with corresponding error and probability

\begin{tabular}{lllllll} 
Probability & 0.95 & 0.90 & 0.85 & 0.80 & 0.75 & 0.50 \\
\hline $\mathrm{GY} \pm 10 \%$ & 23Jul & 19Jul & 16Jul & 14Jul & $11 \mathrm{Jul}$ & 26Jun \\
$\mathrm{GY} \pm 15 \%$ & 14Jul & $11 \mathrm{Jul}$ & 08Jul & 05Jul & 01Jul & 03Jun \\
\hline
\end{tabular}

For part of the precision farming process, the current lead-time prediction offered by the method may appear a bit weak, e.g. to perform real-time early season nitrogen management. However, provided one is ready to cope with more uncertainty (higher confidence boundary and/or alpha risk), the methodology could be used to support part of the decision making. In that way, in Belgium, the last fraction of nitrogen is usually provided between mid-May and early June, for which period the end-season grain yield could already be predicted with 50\% confidence and an error level a bit superior to 15\%. Far more interesting, in Belgium, pesticides (fungicides and insecticides) may still be applied till the mid of July, according to the climatic conditions driving the pest pressure and the corresponding infection risk. In such a case, the ability of the methodology to furnish in real-time the remaining yield potential would easily enable to compute the financial interest of such practices; with the aim to maintain either the yield level if it appears economically justified or to decrease the environmental impact linked to pest application in the other case.

In contrast to the statements made by Porter and Semenov $(1999,2005)$ or Semenov and Porter (1995), this study demonstrated that a mean climate assumption, provided it is appropriately 
recombined with real weather sequences, could be used to perform yield prediction. Based on all these considerations, the presented results clearly show that daily mean climate data could be used as hypothetical projective weather to predict yield in advance.

\section{Conclusion}

In this study the potential of working with daily mean climate variables to supply the unknown hypothetical future was assessed, in order to predict the end-season yield of a wheat crop at field level in Belgium. The STICS crop model was used as a predicting tool, and two kinds of weather information were used: a 30-year weather database was monitored near the experimental field (Ernage site) and a micrometeorological station within the field measured the climatic variables during crop growth. The information was used to build climate matrix ensembles for predicting statistical and real-time within-season final yield. The proposed predictive methodology was combined with the overall historical climate database. It demonstrated that predictive ability was weak early in the season, when measurement duration was short and climate data dependence was high. As the crop growing season progressed, however, the effects of real monitored climate variability played a greater role and the prediction reliability increased. Statistically relevant yield prediction (i.a. with a probability of $85 \%$ and a confidence interval of $10 \%$ around the end-season yield value) could be performed with a reliable predictive delay of about 1 month before harvest. Such a delay on final yield predictions is of great interest to optimise the decision making process related to crop protection. The graphical output also appeared to be a powerful diagnosis tool, enabling the most sensitive and detrimental periods for a given species under the specific soil and climate conditions in a specific area to be identified. Applying the proposed methodology to different management itineraries will allow their relative impacts to be analysed in comparison with the reference situation. This will be a suitable way of determining the optimal cropping system (e.g. most favourable sowing dates, best soil type or cultivar choice). Finally, using the real-time data from the micrometeorological station enabled to $(i)$ predict, daily, potential yield at the local level, (ii) detect stress occurrence daily, and (iii) quantify yield loss (or gain). This realtime application provides the opportunity to make decisions on water irrigation or $\mathrm{N}$ supply within the context of decision rules yet to be defined.

\footnotetext{
Acknowledgements The authors thank the Service Public de Wallonie, Direction Générale Opérationnelle de l'Agriculture, des Ressources naturelles et de l'Environnement (SPW-DGO3) for its financial support for the project entitled 'Suivi en temps réel de l'environnement d'une parcelle agricole par un réseau de microcapteurs en vue d'optimiser l'apport en engrais azotés'. The authors thank also the OptimiSTICS team that allowed them to use the Matlab running code of the STICS model. They are very grateful to CRA-w, especially the Department 'Agriculture et milieu naturel', for the Ernage station climate database and to staff in the ULg- GxABT Geopedological Unit for their soil analyses. Finally, they wish to thank the two anonymous reviewers for their helpful comments.
} 


\section{References}

Basso, B., Bertocco, M., Sartori, L., \& Martin, E. C. (2007). Analyzing the effects of climate variability on spatial pattern of yield in a maize-wheat-soybean rotation. European Journal of Agronomy, 26(2), 82-91, doi:10.1016/j.eja.2006.08.008.

Basso, B., Cammarano, D., Troccoli, A., Chen, D., \& Ritchie, J. T. (2010). Long-term wheat response to nitrogen in a rainfed Mediterranean environment: Field data and simulation analysis. European Journal of Agronomy, 33(2), 132-138, doi:10.1016/j.eja.2010.04.004.

Basso, B., Fiorentino, C., Cammarano, D., Cafiero, G., \& Dardanelli, J. (2012). Analysis of rainfall distribution on spatial and temporal patterns of wheat yield in Mediterranean environment. European Journal of Agronomy, 41(0), 52-65, doi:10.1016/j.eja.2012.03.007.

Basso, B., Ritchie, J. T., Cammarano, D., \& Sartori, L. (2011). A strategic and tactical management approach to select optimal $\mathrm{N}$ fertilizer rates for wheat in a spatially variable field. European Journal of Agronomy, 35(4), 215-222, doi:10.1016/j.eja.2011.06.004.

Bellocchi, G., Rivington, M., Donatelli, M., \& Matthews, K. (2010). Validation of biophysical models: issues and methodologies. A review. Agronomy for Sustainable Development, 30(1), 109-130.

Brisson, N., Gary, C., Justes, E., Roche, R., Mary, B., Ripoche, D., et al. (2003). An overview of the crop model STICS. European Journal of Agronomy, 18(3-4), 309-332, doi:10.1016/s1161-0301(02)00110-7.

Brisson, N., Launay, M., Mary, B., \& Beaudoin, N. (2009). Conceptual basis, formalisations and parameterization of the STICS crop model: Editions Quae. Collection Update Sciences and technologies.

Brisson, N., Mary, B., Ripoche, D., Jeuffroy, M. H., Ruget, F., Nicoullaud, B., et al. (1998). STICS: a generic model for the simulation of crops and their water and nitrogen balances. I. Theory and parameterization applied to wheat and corn. Agronomie, 18(5-6), 311-346.

Campbell, G. S., \& Norman, J. M. (1989). The description and measurement of plant canopy structure. In G. Russell, B. Marshall, \& P. G. Jarvis (Eds.), Plant Canopies : their Growth, Form and Function: Cambridge University Press.

Cantelaube, P., \& Terres, J. M. (2005). Seasonal weather forecasts for crop yield modelling in Europe. Tellus, 57(3), 476-487, doi:10.1111/j.1600-0870.2005.00125.x.

Cantelaube, P., \& Terres, J. M. (2003). Use of Seasonal Forecasts on Crop Yield Modelling. Publication of the European Commission, EUR 20996 EN.

Challinor, A. J., Slingo, J. M., Wheeler, T. R., \& Doblas-Reyes, F. J. (2005). Probabilistic simulations of crop yield over Western India using the DEMETER seasonal hindcast ensembles. Tellus, 57(3), 498-512, doi:10.1111/j.1600-0870.2005.00126.x.

Dumont, B., Leemans, V., Mansouri, M., Bodson, B., Destain, J-P., \& Destain, M-F. (2013). Parameter identification of the STICS crop model, with an accelerated formal MCMC approach. Environmental Modelling and Software, 54, 121-135.

Ewert, F., van Ittersum, M. K., Heckelei, T., Therond, O., Bezlepkina, I., \& Andersen, E. (2011). Scale changes and model linking methods for integrated assessment of agri-environmental systems. Agriculture, Ecosystems \& Environment, 142(1-2), 6-17, doi:10.1016/j.agee.2011.05.016.

Hansen, S., Jensen, H. E., Nielsen, N. E., \& Swenden, H. (1990). Daisy, a soil plant system model. Danish simulation model for transformation and transport of energy and matter in the soil plant atmosphere system. The National Agency for Environment Protection, Copenhagen, pp. 369.

Hewitt, C. D. (2004). Ensembles-based predictions of climate changes and their impacts. Eos Trans. AGU, 85(52), doi:10.1029/2004eo520005.

Jamieson, P. D., Semenov, M. A., Brooking, I. R., \& Francis, G. S. (1998). Sirius: a mechanistic model of wheat response to environmental variation. European Journal of Agronomy, 8(3-4), 161-179, doi:10.1016/s1161-0301(98)00020-3.

Lawless, C., \& Semenov, M. A. (2005). Assessing lead-time for predicting wheat growth using a crop simulation model. Agricultural and Forest Meteorology, 135(1-4), 302-313, doi:10.1016/j.agrformet.2006.01.002.

Mansouri, M., Dumont, B., \& Destain, M-F. (2013). Modeling and prediction of nonlinear environmental system using Bayesian methods. Computers and Electronics in Agriculture, 92(0), 16-31. 
Mavromatis, T., \& Hansen, J. W. (2001). Interannual variability characteristics and simulated crop response of four stochastic weather generators. Agricultural and Forest Meteorology, 109(4), 283-296, doi:10.1016/s0168-1923(01)00272-6.

Mavromatis, T., \& Jones, P. D. (1998). Comparison of climate change scenario construction methodologies for impact assessment studies. Agricultural and Forest Meteorology, 91(12), 51-67, doi:10.1016/s0168-1923(98)00063-x.

McBratney, A., Whelan, B., Ancev, T., \& Bouma, J. (2005). Future directions of precision agriculture. Precision Agriculture, 6(1), 7-23, doi:10.1007/s11119-005-0681-8.

Naud, C., Makowski, D., \& Jeuffroy, M-H. (2008). Is it useful to combine measurements taken during the growing season with a dynamic model to predict the nitrogen status of winter wheat? European Journal of Agronomy, 28, 291-300

Nonhebel, S. (1994a). The effects of use of average instead of daily weather data in crop growth simulation models. Agricultural Systems, 44(4), 377-396, doi:10.1016/0308$521 \times(94) 90194-\mathrm{k}$.

Nonhebel, S. (1994b). Inaccuracies in weather data and their effects on crop growth simulation results: 1. Potential production. Climate Research, 4, 47-60.

Palmer, T. N., Doblas-Reyes, F. J., Hagedorn, R., Alessandri, A., Gualdi, S., Andersen, U., et al. (2004). Development of a European multi-model ensemble system for seasonal to interannual prediction (DEMETER). Bulletin of the American Meteorological Society, 85(6), 853-872, doi:10.1175/bams-85-6-853.

Palmer, T. N., Doblas-Reyes, F. J., Hagedorn, R., \& Weisheimer, A. (2005). Probabilistic prediction of climate using multi-model ensembles : from basics to applications. Philosophical Transactions of the Royal Society B: Biological Sciences, 360(1463), 19911998.

Palosuo, T., Kersebaum, K. C., Angulo, C., Hlavinka, P., Moriondo, M., Olesen, J. E., et al. (2011). Simulation of winter wheat yield and its variability in different climates of Europe: A comparison of eight crop growth models. European Journal of Agronomy, 35(3), 103114

Porter, J. R., \& Semenov, M. A. (1999). Climate variability and crop yields in Europe. Nature, 400(6746), 724-724.

Porter, J. R., \& Semenov, M. A. (2005). Crop responses to climatic variation. Philosophical Transactions of the Royal Society B: Biological Sciences, 360(1463), 2021-2035.

Racsko, P., Szeidl, L., \& Semenov, M. (1991). A serial approach to local stochastic weather models. Ecological Modelling, 57(1-2), 27-41, doi:10.1016/0304-3800(91)90053-4.

Riha, S. J., Wilks, D. S., \& Simoens, P. (1996). Impact of temperature and precipitation variability on crop model predictions. Climatic Change, 32(3), 293-311, doi:10.1007/bf00142466.

Ritchie, J. T., \& Otter, S. (1984). Description and performance of CERES-Wheat, a user oriented wheat yield model. USDA-ARS-SR Grassland Soil and Water Research Laboratory, Temple, TX, pp. 159-177.

Semenov, M.A. (2008). Simulation of weather extreme events by stochastic weather generator. Climate Research, 35, 203-212.

Semenov, M. A., \& Barrow, E. M. (1997). Use of a stochastic weather generator in the development of climate change scenarios. Climatic Change, 35(4), 397-414, doi:10.1023/a:1005342632279.

Semenov, M. A., \& Doblas-Reyes, F. J., (2007). Utility of dynamical seasonal forecasts in predicting crop yield. Climate Research, 34(1), 71-81.

Semenov, M., \& Porter, J. (1995). Climatic variability and the modelling of crop yields. Agricultural and Forest Meteorology, 73(3-4), 265-283, doi:10.1016/0168-1923(94)05078$\mathrm{k}$.

Singh, A. K., Tripathy, R., \& Chopra, U. K. (2008). Evaluation of CERES-Wheat and CropSyst models for water-nitrogen interactions in wheat crop. Agricultural Water Manage., 95, 776-786.

Singh, U., \& Thornton, P. K. (1992). Using crop models for sustainability and environmental quality assessment. Outlook on agriculture, 21(3) : (Eds.) Turpin, Herts, ROYAUME-UNI (1956).

Tey, Y., \& Brindal, M. (2012). Factors influencing the adoption of precision agricultural technologies: a review for policy implications. Precision Agriculture, 13(6), 713-730, doi:10.1007/s11119-012-9273-6.

Van Diepen, C. A., Wolf, J., Van Keulen, H., \& Rappoldt, C. (1989). WOFOST : a simulation model of crop production. Soil Use Manage, 5, 16-24.

Vrugt, J. A., Braak, C. J. F. T., Diks, C. G. H., Robinson, B. A., Hyman, J. M., \& Higdon, D. (2009). Accelerating Markov chain Monte Carlo simulation by differential evolution with 
self-adaptive randomized subspace sampling. International Journal of Nonlinear Sciences and Numerical Simulation, 10(3), 273-290.

William, J. R., Jones, C. A., Kiniry, J. R., \& Spanel, D. A. (1989). The EPIC crop growth model. Trans ASAE, 32, 497-511. 